\title{
Room temperature vibrational photoluminescence and field emission of nanoscaled tris-(8-hydroxyquinoline) aluminum crystalline film
}

\author{
Jiann-Jong Chiu and Way-Seen Wang ${ }^{\text {a) }}$ \\ Department of Electrical Engineering, National Taiwan University, Taipei, Taiwan 106, R.O.C. \\ Chi-Chung Kei, Chun-Pey Cho, and Tsong P. Perng ${ }^{\text {b) }}$ \\ Department of Materials Science and Engineering, National Tsing Hua University, Hsinchu, Taiwan 300, R.O.C. \\ Pei-Kuen Wei and Sheng-Yu Chiu \\ Institute of Applied Science and Engineering Research, Academia Sinica, Taipei, Taiwan 115, R.O.C.
}

(Received 11 August 2003; accepted 1 October 2003)

\begin{abstract}
The nanoscaled tris-(8-hydroxyquinoline) aluminum $\left(\mathrm{AlQ}_{3}\right)$ crystalline film was synthesized by vapor condensation. It was stacked with nanometer-sized rods, approximately $100 \mathrm{~nm}$ wide and 1 $\mu \mathrm{m}$ long, and had a surface roughness of about $100 \mathrm{~nm}$. The vibronic progression with several separated peaks was observed in the photoluminescence spectrum at room temperature. It is attributed to the crystallinity of $\mathrm{AlQ}_{3}$ and the coupling of vibrations of the individual ligands to the fluorescence transition. The emission current was also observed with a turn-on field of $12.0 \mathrm{~V} / \mu \mathrm{m}$, and a current density of about $0.8 \mathrm{~mA} / \mathrm{cm}^{2}$ at $22 \mathrm{~V} / \mu \mathrm{m}$. Therefore, the $\mathrm{AlQ}_{3}$ crystalline film provides a choice for field emission. (C) 2003 American Institute of Physics.
\end{abstract}

[DOI: $10.1063 / 1.1629798$ ]

Recently, a lot of attention has been paid to conducting polymers and small-molecule organic semiconductors due to many unique properties such as flexibility, high photoconductivity, and nonlinear optical effects that may offer applications in optoelectronic devices. ${ }^{1}$ Since high efficiency and good performance of tris-(8-hydroxyquinoline) aluminum $\left(\mathrm{AlQ}_{3}\right)$ based organic light emitting diodes (OLEDs) was reported by Tang and VanSlyke, ${ }^{2} \mathrm{AlQ}_{3}$ has been widely used in the electron transport layer of OLEDs. Many studies have then been focused on the thermal, electrical, and optical properties of $\mathrm{AlQ}_{3}$ to improve the characteristics of the devices. ${ }^{3}$ Compared with other aromatic compounds, ${ }^{4} \mathrm{AlQ}_{3}$ has a relatively high melting point $\left(419^{\circ} \mathrm{C}\right)$ and glass transition temperature $\left(177^{\circ} \mathrm{C}\right)$ that contribute to the formation of amorphous $\mathrm{AlQ}_{3}$ film. The film yields a single-peaked and broadened photoluminescence (PL) spectrum under certain applied voltage or exposure to an incident laser. However, some reports revealed that crystalline $\mathrm{AlQ}_{3}$ films could be prepared by thermal evaporation on heated substrates, ${ }^{5}$ and some special nanostructures could also be synthesized by depositing on liquid nitrogen-cooled substrates. ${ }^{6,7}$ Furthermore, it was reported that the crystalline film had a different fluorescence quantum yield and charge mobility compared with those of the amorphous film, which was ascribed to the polymer alignment. ${ }^{8}$ In this work, the room temperature vibrational PL spectrum and field emission of nanoscaled $\mathrm{AlQ}_{3}$ crystalline film are presented.

Nanoscaled $\mathrm{AlQ}_{3}$ crystalline film was synthesized by vapor condensation in $\mathrm{Ar}$ at $1.33 \times 10^{-3} \mathrm{~Pa} .{ }^{6,7}$ The $\mathrm{AlQ}_{3}$ powder was placed in a graphite boat. The silicon wafer or indium tin oxide (ITO) coated glass substrate was attached under a liquid nitrogen cold trap, which was kept at $10 \mathrm{~cm}$

\footnotetext{
${ }^{a)}$ Electronic mail: wswang@cc.ee.ntu.edu.tw

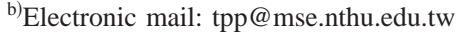

above the graphite boat. The $\mathrm{AlQ}_{3}$ powder was sublimed at a boat temperature of $400{ }^{\circ} \mathrm{C}$, which was regulated by a power supply and a $K$-type thermocouple. The microstructure was observed by means of field emission gun scanning electron microscopy (FEGSEM), as shown in Fig. 1(a). The $\mathrm{AlQ}_{3}$ film is stacked by nanometer-sized rods, which are about 100 $\mathrm{nm}$ wide and $0.5-1 \mu \mathrm{m}$ long. The surface morphology was also examined by atomic force microscopy (AFM), as displayed in Fig. 1(b). The roughness of the surface is about $100 \mathrm{~nm}$, as shown in Fig. 1(c).

A polarization-modulation near-field scanning optical microscopy (PM-NSOM) $)^{8,9}$ was employed to verify the crystallinity of the nanorods. As the combination of conventional polarization microscopy and near-field scanning optical microscope provides the image of crystalline domains with a resolution less than $100 \mathrm{~nm},{ }^{10}$ it is feasible to investigate the nanocrystalline domains of the $\mathrm{AlQ}_{3}$ film. In this work, the incident laser has a wavelength of $400 \mathrm{~nm}$, close to the absorption band of the $\mathrm{AlQ}_{3}$. The incident light was modulated to form a rotated linearly polarized light. In a crystalline domain, the absorption varies with the direction of linear polarization. Therefore, a dichroic ratio $(R)$ and a phase signal $(\theta)$ can be measured through the polarizationmodulation technique. The dichroic ratio $(R)$ is defined as ${ }^{8}$

$$
R=\frac{I_{\|}-I_{\perp}}{I_{\|}+I_{\perp}}
$$

where $I_{\|}$and $I_{\perp}$ are the transmission light intensities that are parallel and perpendicular to the principal crystalline axis, respectively. The phase signal is the orientation angle where the direction of linearly polarized light coincides with the principal crystalline axis. ${ }^{8}$ The dichroic ratio is related to the degree of crystallinity and the phase image is related to the 


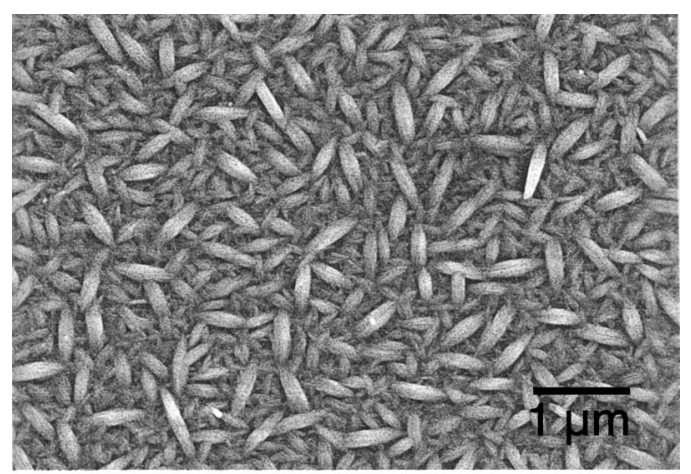

(a)

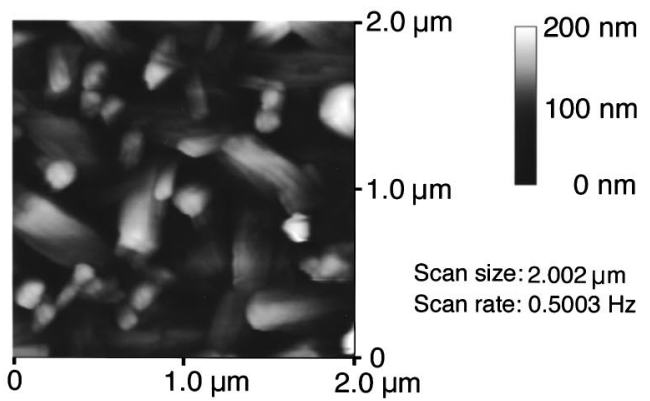

(b)

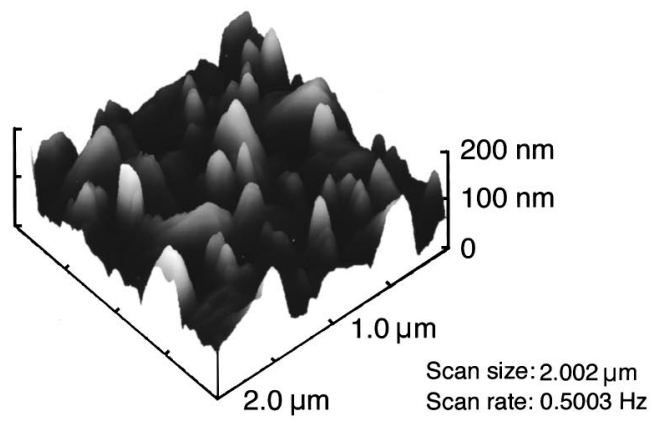

(c)

FIG. 1. Microstructures of the $\mathrm{AlQ}_{3}$ crystalline film: (a) FEGSEM image, (b) AFM image, and (c) roughness of surface.

alignment direction of the domain. The dichroic and phase images of the $\mathrm{AlQ}_{3}$ crystalline film are shown in Fig. 2. According to the dichroic image, Fig. 2(a), the crystallized regions are clearly found in the bright area. The dichroic ratio has a maximum value of about 0.37 . The phase image with a value varying from $-90^{\circ}$ to $+90^{\circ}$ is displayed in Fig. 2(b). Compared to the dichroic image, the phase image reveals the directions of crystalline domains. The angle is the same in a single domain and is different for each domain. The crystalline film of $\mathrm{AlQ}_{3}$ has also been reported previously, ${ }^{5}$ although both films were grown by different mechanisms. Moulin et al..$^{5}$ fabricated the $\mathrm{AlQ}_{3}$ crystalline film on an oriented polytetrafluoroethylene substrate at temperatures in the range of $50-100^{\circ} \mathrm{C}$. In this work, the crystalline film was grown on an ITO substrate at $-196^{\circ} \mathrm{C}$.

To check if the $\mathrm{AlQ}_{3}$ molecules are decomposed during evaporation, the chemical bondings of the $\mathrm{AlQ}_{3}$ crystalline film and original powder were examined by Fouriertransform infrared spectrum. Except for the peaks due to $\mathrm{CO}_{2}$ and $\mathrm{H}_{2} \mathrm{O}$, all the other absorption peaks between 400 and $2000 \mathrm{~cm}^{-1}$ are in good agreement with the reported

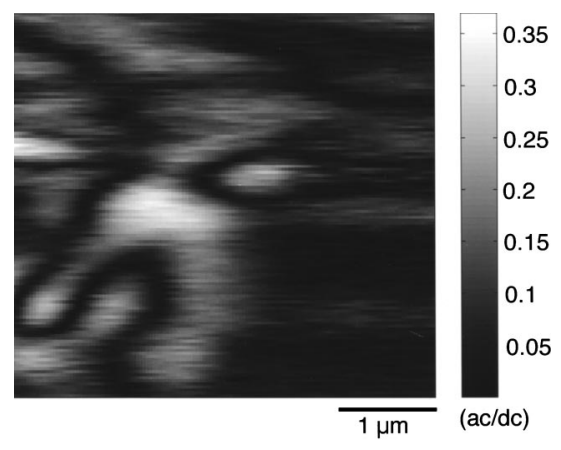

(a)

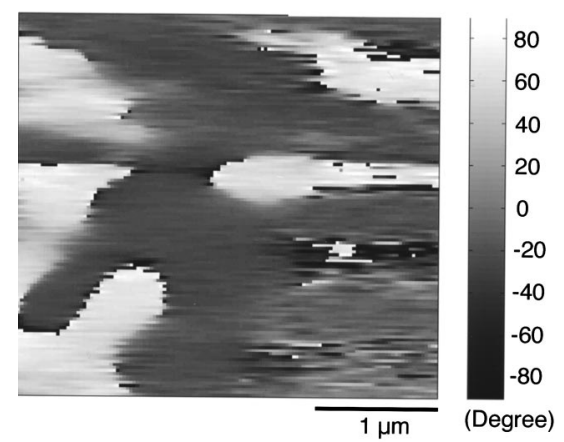

(b)

FIG. 2. PM-NSOM images of the $\mathrm{AlQ}_{3}$ crystalline film: (a) dichroic ratio image and (b) phase image.

results. ${ }^{11}$ The absorption peaks of the crystalline film are the same as those of the $\mathrm{AlQ}_{3}$ powder, indicating that the bonding of the molecule is preserved even after evaporation at $400{ }^{\circ} \mathrm{C}$.

The PL spectra of $\mathrm{AlQ}_{3}$ amorphous and crystalline films deposited on silicon substrate were obtained by exciting with a $\mathrm{He}-\mathrm{Cd}$ laser of a wavelength $325 \mathrm{~nm}$ and power $50 \mathrm{~mW}$. The amorphous film of a thickness $1200 \AA$ was deposited at $1.33 \times 10^{-3} \mathrm{~Pa}$ with a disposition rate of $3-5 \AA / \mathrm{s}$ controlled by a quartz monitor. It yields a strong and smooth green visible light luminescence ranging from 4500 to $7000 \AA$ with the maximum intensity at about $5380 \AA$, as shown in Fig. 3(a). On the contrary, vibronic evolution of PL spectrum was observed from the $\mathrm{AlQ}_{3}$ crystalline film, as shown in Fig. 3(b). In ordered organic molecular solids, the vibronic progression with several separated peaks have been shown previously, but only in the spectrum of $\mathrm{AlQ}_{3}$ crystalline sample measured at $4.2 \mathrm{~K} .{ }^{12}$ Here the vibronic progression in the PL spectrum of $\mathrm{AlQ}_{3}$ crystalline film is measured at room temperature. It is reported that the splitting of the peaks is attrib-

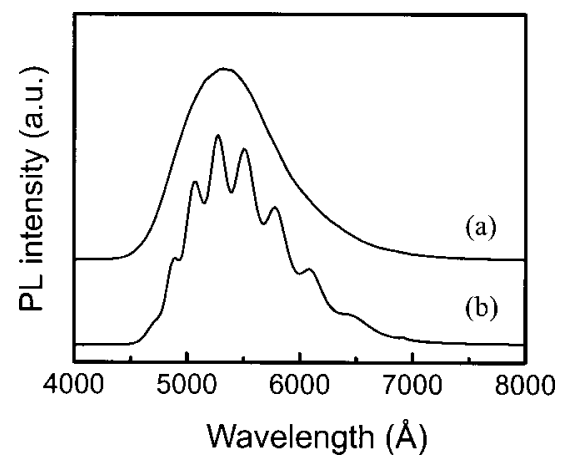

FIG. 3. PL spectra of the $\mathrm{AlQ}_{3}$ films: (a) amorphous and (b) crystalline. 


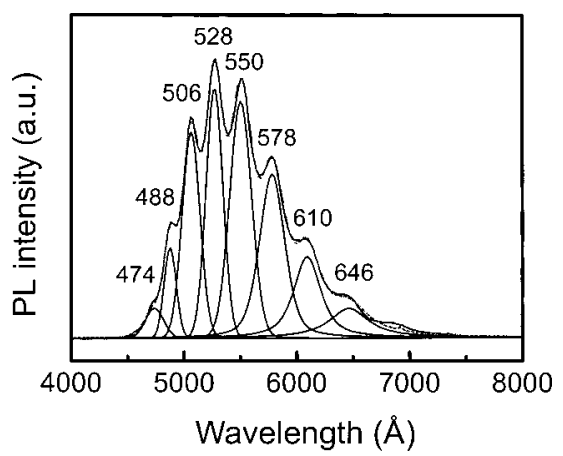

FIG. 4. Vibronic progression of PL spectrum and its curve-fitting.

uted to the coupling of vibrations of the individual ligands to the fluorescence transition. ${ }^{13}$ After fitting the vibrational PL spectrum, the locations of individual peaks are positioned at $474,488,506,528,550,578,610$, and $646 \mathrm{~nm}$ as shown in Fig. 4. The average spacing of these peaks is about 800 $\mathrm{cm}^{-1}$, which is larger than $655-700 \mathrm{~cm}^{-1}$ reported elsewhere. ${ }^{13}$

Field emission of polycrystalline diamond film has been observed for many years. ${ }^{14}$ Recently, $\mathrm{AlQ}_{3}$ nanowires have been fabricated and shown to exhibit field emission. ${ }^{7}$ The $\mathrm{AlQ}_{3}$ polycrystalline film reported here is an organic semiconductor that shows field emission with a relatively low turn on voltage. The field emission properties were measured with a $50 \mu \mathrm{m}$ gap between the anode and the cathode at a base pressure of $1.0 \times 10^{-5} \mathrm{~Pa}$. A spherical-shaped platinum probe with an estimated area of $1.6 \times 10^{-3} \mathrm{~cm}^{2}$ was used as the anode. The $\mathrm{AlQ}_{3}$ polycrystalline film was deposited on an ITO coated glass substrate and acted as the cathode. The field emission instrumentation has a sphere-to-plate geometry rather than plane-to-plane, because the platinum probe provides precise motion and manipulation inside the high vacuum environment. Therefore, the field emission properties in any region of the film can be measured. The field emission characteristics are presented by the curve of current density $J$ versus applied field $E$, as shown in Fig. 5(a). The turn-on field is $12.0 \mathrm{~V} / \mu \mathrm{m}$ when the current density reaches $0.01 \mathrm{~mA} / \mathrm{cm}^{2}$. The field emission yields a current density of about $0.8 \mathrm{~mA} / \mathrm{cm}^{2}$ at $22 \mathrm{~V} / \mu \mathrm{m}$. The Fowler-Nordheim plot of $\ln \left(J / E^{2}\right)$ vs $1 / E$, shown in the inset of Fig. 5(a), yields a straight line demonstrating the field emission phenomenon. ${ }^{15}$ The stability test of the $\mathrm{AlQ}_{3}$ polycrystalline film was performed with an initial current density of about $0.35 \mathrm{~mA} / \mathrm{cm}^{2}$ and an applied field of $20 \mathrm{~V} / \mu \mathrm{m}$ for more than $2000 \mathrm{~s}$, as illustrated in Fig. 5(b). The field emission current varied when different region of the film was measured by the platinum probe. It revealed that the field emission current was strongly dependent on the surface roughness of the film. According to the AFM image shown in Fig. 1(c), the polycrystalline film is stacked with nanometer-sized rods and the roughness of the surface depth is about $100 \mathrm{~nm}$. It demonstrates that the electrons may emit from the bumps of the $\mathrm{AlQ}_{3}$ film at high voltages. The effect of surface roughness on electron emission from polycrystalline diamond films has

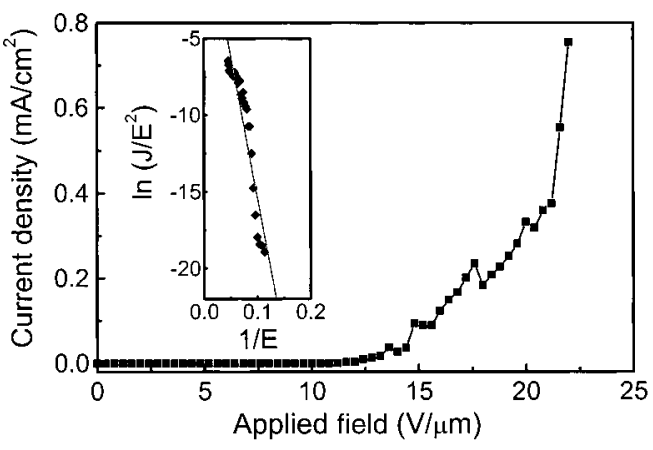

(a)

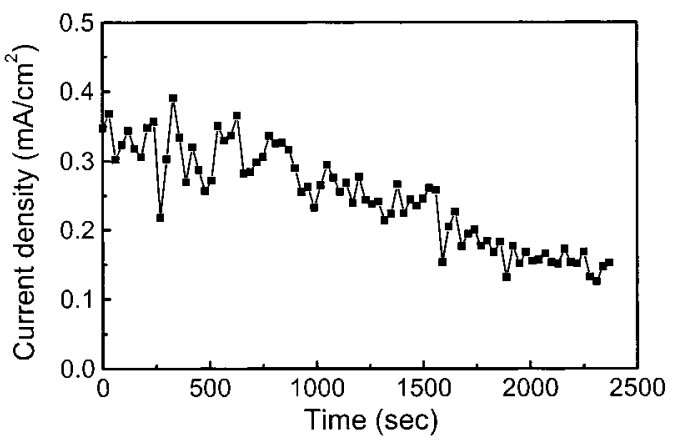

(b)

FIG. 5. (a) Field emission of the $\mathrm{AlQ}_{3}$ polycrystalline film. The inset shows the Fowler-Nordheim plot. (b) Field emission stability of the $\mathrm{AlQ}_{3}$ polycrystalline film tested at $20 \mathrm{~V} / \mu \mathrm{m}$ for more than $2000 \mathrm{~s}$.

been reported, ${ }^{14}$ but the same mechanism for a small molecular organic semiconductor is demonstrated here.

This work was supported by the National Science Council of ROC under Contract No. NSC-91-2215-E-002-024 and Ministry of Education of ROC under Contract No. A-91-EFA04-1-4. The authors are grateful to Teng-Fang Kuo and Hong-Jen Lai of Materials Research Laboratory of the Industrial Technology Research Institute, Taiwan, ROC, for their help in the measurement of field emission.

${ }^{1}$ Y. Cao, I. D. Parker, G. Yu, C. Zhang, and A. J. Heeger, Nature (London) 397, 414 (1999).

${ }^{2}$ C. W. Tang and S. A. VanSlyke, Appl. Phys. Lett. 51, 913 (1987).

${ }^{3}$ M. D. Halls and H. B. Schlegel, Chem. Mater. 13, 2632 (2001).

${ }^{4}$ K. Naito and A. Miura, J. Phys. Chem. 97, 6240 (1993).

${ }^{5}$ J. F. Moulin, M. Brinkmann, A. Thierry, and J. C. Wittmann, Adv. Mater. (Weinheim, Ger.) 14, 436 (2002).

${ }^{6}$ J. J. Chiu, W. S. Wang, C. C. Kei, and T. P. Perng, Appl. Phys. Lett. 83, 347 (2003).

${ }^{7}$ J. J. Chiu, C. C. Kei, T. P. Perng, and W. S. Wang, Adv. Mater. (Weinheim, Ger.) 15, 1361 (2003).

${ }^{8}$ P. K. Wei and W. S. Fann, J. Microsc. 202, 148 (2001).

${ }^{9}$ P. K. Wei, S. Y. Chiu, and W. L. Chang, Rev. Sci. Instrum. 73, 2624 (2002).

${ }^{10}$ E. Betzig and J. K. Trautman, Science 257, 189 (1992).

${ }^{11}$ M. D. Halls and R. Aroca, Can. J. Chem. 76, 1730 (1998).

${ }^{12}$ M. Brinkmann, G. Gadret, M. Muccini, C. Taliani, N. Masciocchi, and A. Sironi, J. Am. Chem. Soc. 122, 5147 (2000).

${ }^{13}$ G. P. Kushto, Y. Iizumi, J. Kido, and Z. H. Kafafi, J. Phys. Chem. A 104, 3670 (2000).

${ }^{14}$ N. Koenigsfeld, R. Kalish, A. Cimmino, D. Hoxley, S. Prawer, and I. Yamada, Appl. Phys. Lett. 79, 1288 (2001).

${ }^{15}$ V. V. Zhirnov, C. L. Rinne, G. J. Wojak, R. C. Sanwald, and J. J. Hren, J. Vac. Sci. Technol. B 19, 87 (2001). 
Applied Physics Letters is copyrighted by the American Institute of Physics (AIP). Redistribution of journal material is subject to the AIP online journal license and/or AIP copyright. For more information, see http:/ojps.aip.org/aplo/aplcr.jsp

Copyright of Applied Physics Letters is the property of American Institute of Physics and its content may not be copied or emailed to multiple sites or posted to a listserv without the copyright holder's express written permission. However, users may print, download, or email articles for individual use. 